https://doi.org/10.46344/JBINO.2021.v10i02.29

\title{
PSYCHOLOGICAL SATISFACTION OF ELDERLY PEOPLE FOR MEETING THE BASIC PSYCHOLOGICAL NEEDS
}

\author{
REEJA RAJU K, NEERAJ KUMAR BANSAL
}

Associate Professor, Jai Institute of Nursing \& Research, Gwalior

Introduction: Ageing which is a natural and universal phenomenon has multidimensional process which is not only viewed as biological and medical concern alone but of social, economic, psychological and demographical importance. The three basic needs given by Edward L. Deci and Richard M. Ryan in their work Self-Determination Theory (SDT) is very much necessary to be fulfilled. It provides an account of the motivational processes by which an elder individual seek autonomy and self-expression within the context of social relationships. SDT postulates the existence of three basic needs: autonomy, competence, and relatedness. A descriptive study was carried out with the objectives; 1 ) to assess the level of psychological satisfaction of elderly people in meeting their basic psychological needs; 2) to find out the association between the levels of psychological satisfaction of elderly people in meeting their basic psychological needs with selected demographic variables

\section{Need for the study}

The demographic transition commonly known as the 'graying of age' is posing a challenge to the entire world. Population aging is an inevitable product of demographic transition. Changes in demographic components namely fertility mortality and migration determine the age structure of the population. The changes in the demographic structure of the societies during the last few decades, particularly in developing countries, have made aged a socially noticeable section of society.

The rapidly growing elderly population presents many several psychological problems. As the elderly people sometimes think that they are unable to do anything and not useful for family, friends and others as well as for the community. So, they do not like to take care of themselves perfectly. So, there is need to make them aware of taking care of their health by themselves for longevity of healthy life.

KEY WORDS: psychological satisfaction, SDT, autonomy, competence, relatedness.

\section{Objectives}

O assess the level of psychological satisfaction of elderly people in meeting their basic psychological needs. 
o find out the association between the level of psychological satisfaction of elderly people in meeting their basic psychological needs with selected demographic variables.

\section{Review of Literature}

Suhara Beevi conduct study on aging is a universal phenomenon and natural biological process of the lifecycle. The United Nation defines a country as 'aging' when the proportion of people over 60 years reaches 7 percent. India exceeded that rate of proportion with 7.8 percent in 2001 and India comes under the purview of the UN definition of 'ageing country'. The number of elderlies was 77 million in 2001 and is expected to cross 100 million in 2013 and 177 million by the year 2025.

Nandi and Manju conduct study the average life span is increasing by an average of 2 years every decade. India is one of the sear countries. The life expectancy in India had doubled from 32 years in 1947 to 62 years in 1995. The absolute member of elderly has grown from 19 million to 70 million in the same period. By the year 2020, the estimate population of the elderly will be 142 million or about $11 \%$ of the country's population.

\section{Methodology:}

he research approach used in this study is survey approach. It is considered by the investigator as the most suitable one for this study. It is used to assess the psychological satisfaction for meeting the basic psychological needs among elderly people.

\section{$T$}

he research design adopted for the study is descriptive research

he present study was carried out among 100 elderly people of selected areas of Gwalior city, M.P.

urposive sampling was used to collect the sample.

structured interview schedule was used to collect the data. The tool contained questions related to autonomy, competence and relatedness.

nalysis was done through descriptive and inferential statistics and represented in graphs and tables.

\section{Results:}

Majority of the elder people (52\%) were of the age group $70-80$ years, $(38 \%)$ were of $60-70$ years and the rest $(10 \%)$ in the age above 80 . Most of the elderly people were male $(71 \%)$ and the rest $(29 \%)$ were female. As regard to type of family majority of the elderly people (60\%) in joint family and $(34 \%)$ in nuclear family. As regard to the marital status (89\%) of elderly people were married, (9\%) widow/widower and the rest (2\%) were unmarried. As regard to occupation (29\%) of elderly people were businessman and had no job respectively, (22\%) were service people and the rest $(20 \%)$ were pensioner.

Comparison of mean \& standard deviation of psychological satisfaction scores of elderly people in meeting basic psychological needs shows that $78 \%$ of elderly people have moderate level of psychological satisfaction (80-120) with 
mean of 99.43 and SD of 10.26. High level of psychological satisfaction contains $18 \%$ of elderly people who scored between 120-160 with mean of 130.88 and SD of 6.91, only 4 candidates categorized in low level of psychological satisfaction on the basis of their scores.

The mean score of level of psychological satisfaction of elderly people for meeting basic psychological needs was 104.02, which was considered in moderate level of psychological satisfaction. There was no association found between scores and age, religion, type of family, marital status, head of family status, number of children and occupation but there is association with gender and education.

The above findings show that the people who are more elderly are more satisfied in comparison of less elderly. This might be because less elderly people face more problems in job, family satisfaction and other interference responsibilities.

Discussion: findings of the study indicate that there is a need to give more care and understanding to elderly people. There must be more rights and privileges for them to provide better care and to prevent further complications in them.

\section{Implications:}

The findings of the study have implication for nursing administration, nursing practice, nursing education and nursing research.

\section{Nursing Administration:}

- Grief exist programs are to be introduced in geriatric department for nurses so that they can share their personal problems, adjustment problems \& other problems related to work.
- The nurses posted in various wards/units should be trained through in-service education to possess the required knowledge, skill and attitude regarding how to interact with elderly people.

- As a part of nursing administration, the nurse administrator plays a vital role in educating clients and taking up health promotive activities for elderly people.

- Necessary administrative support should be provided to conduct educational programs in all health setting.

\section{Nursing Practice:}

- Special training programs in geriatric nursing care are likely to strengthen her confidence to face stressful situations in working with elderly people.

- Nurses must educate the family by giving mass health education and individual health education.

- Moreover, nurses need to participate in public awareness program through mass media.

- Encourage the elderly people to participate actively in health awareness campaign.

\section{Nursing Education:}

- Nursing students after completion of their training whether they would be at general hospital, psychiatric hospital or in community, they need to be provided with adequate experience with elderly people.

- In the nursing curriculum, emphasis needs to be placed related to geriatric problems and their solutions. Nursing students should be taught about geriatric problem and its home management.

- This will help them to educate the elderly people to modify their life style and take 
necessary action whenever they feel isolated or pressurized.

- Nurse educator can give emphasis to remove misconceptions about the aging process.

- Nurse educator need to lay more emphasis on community gerontological nursing to train students to work with groups of elder people.

\section{Nursing Research:}

- Nursing research should be directed for exploring \& updating the elderly people's ability to cope with problems arising in their daily life.

- Nursing research should be directed towards assessing the knowledge of nursing personnel in terms of providing care in geriatric care setting.

\section{Limitations:}

- This study was confined to 100 elderly people from selected area of Gwalior city.

- Limited time was available for data collection.

- Random sampling could not be applied due to limited period of study.

- Standardized tool could not be located by the investigator, so developed the tool for the study.

- Non probability purposive sampling limits the generalization of findings.

\section{Recommendations:}

- The study can be replicated on a large sample for making wider generalizations.

- A comparative study can be conducted among rural and urban geriatric.

- A comparative study can be conducted among male and female elderly people.

- A study can be conducted to assess attitude of nursing personal towards the elderly people in caring and supporting them.
- More Counselling centers for elderly people must be started.

- A study can be conducted to assess the psychological satisfaction for meeting other psychological needs.

\section{References:}

- Journal of Counselling Psychology: Dynamic processes underlying adult attachment organization, Vol 47, Issue:4, November 2002, Pp-283-301.

- Journal of Counselling \& Development: Adult attachment orientations and college student distress: The mediating role of problem coping styles, Vol 79, Issue 10, October 2004, Pp- 459-464.

- Journal of Personality and Social Psychology, Within-person variation in security of attachment: A selfdetermination theory perspective on attachment, need fulfilment, and wellbeing, Vol 72, January 2000, Pp-367-384.

- Journal of Counselling Psychology, Attachment, social competencies, social support, and psychological distress, Vol 52, Issue 6, Pp- 358-367.

- Journal of Counselling Psychology, Analyzing data from experimental studies: A latent variable structural equation modelling approach, Vol 45, Pp-18-29.

- Journal of Personality and Social Psychology, what is satisfying about satisfying events? Testing 10 candidate psychological needs, Vol 80, Pp- 325-339.

- Journal of Personality and Social Psychology, Effects of externally mediated rewards on intrinsic motivation., Vol 18, Issue 13, Pp-105-115. 